\title{
Recent Advances in the Associations of Advanced Glycation End Products (Ages) and Cancer
}

\author{
Qiuyu Wang1*, Congxiao Zhang ${ }^{2}$ and Nessar Ahmed ${ }^{1}$ \\ ${ }^{1}$ Department of Life Sciences, Manchester Metropolitan University, UK \\ ${ }^{2}$ Department of Stomatology, the First Hospital of JiLin University, China \\ *Corresponding author: Qiuyu Wang, Department of Life Sciences, Manchester Metropolitan University, Manchester, UK \\ To Cite This Article: Qiuyu Wang. Recent Advances in the Associations of Advanced Glycation End Products (Ages) and Cancer. Am J Biomed Sci \& \\ Res. 2019 - 5(2). AJBSR.MS.ID.000888. DOI: 10.34297/AJBSR.2019.05.000888.
}

Received: 畊August 28, 2019; Published: 畊 September 13, 2019

\begin{abstract}
Advanced glycation end products (AGEs) are reactive metabolites under physiological and pathological conditions. They accumulate in tissues and organs and are involved in the pathogenesis of various diseases including cancer. This review presents recent findings on the roles of AGEs and their receptor (RAGE) in carcinogenesis. The molecular mechanisms of cancer pathogenesis and progression related to AGEs-RAGE interaction are highlighted. The strategies for AGE reduction and inhibition in the potential prevention and treatment of cancers are discussed.
\end{abstract}

Keywords: Advanced glycation end products; rReceptor for advanced glycation end products; Glycation; Cancer

Abbreviations: AGEs: Advanced Glycation End Products; RAGE: Receptor for Advanced Glycation End Products; ROS: Reactive Oxygen Species; SNP: Single Nucleotide Polymorphism

\section{Mini Review}

Advanced glycation end products (AGEs) are a group of heterogeneous molecules formed by non-enzymatic reactions. These reactions occur between the carbonyl group of reducing sugars, such as glucose, fructose, ADP-ribose, or dicarbonyl derivatives such as glyoxal, methyl glyoxal, 3-deoxyglucosone, and the nucleophilic amino group of proteins, lipids or nucleic acids $[1,2]$. Advanced glycation end products are generated exogenously in food, especially in thermal processed food, but are also produced endogenously under physiological or pathological conditions $[1,3,4]$. In vivo glycation takes place slowly but continuously throughout life. The accumulation of AGEs has been linked to agerelated diseases including diabetes mellitus, atherosclerosis and cancer $[5,6,7]$.

Advanced glycation end products can be divided into fluorescent and nonfluorescent forms, as well as cross- and non-cross-linked types. The commonest AGEs are 3-deoxyglucosone-derived pyrraline and pentosidine, glyoxal- or methyl glyoxal-derived $\mathrm{N} \varepsilon$ (carboxylmethyl)-L-lysine (CML), the cross-linked glyoxal-lysine dimer (GOLD), and methylglyoxal-lysine dimer (MOLD) and S-carboxymethylcysteine. It has been shown that the levels of these compounds are high in plasma and tissues during aging as well as in various cancers $[8,9]$.
The underlying mechanisms of AGE formation include the Maillard reaction, the polyol and glycolysis pathways, lipid peroxidation, and high oxidative stress, almost all of which require a hyper glycemic cellular microenvironment. Cancer cells are characterized by an increased glucose uptake and a high rate of glycolysis (the Warburg effect), to meet their energy requirements. Consequently, under hyper glycemic conditions, glycation is increased in cancer cells and AGE accumulation is accelerated. The gradual build-up of AGEs is involved in the pathogenesis and development of cancers $[10,11]$.

Cancer patients show increased AGE levels in their tumour tissues, plasma and in their serum samples $[12,13]$. For example, primary colorectal carcinoma tissue displays a higher intensity of AGE expression compared with normal colonic mucosa [14]. The serum concentrations of glucose-derived AGEs in gastric cancer patients without diabetes are found to be markedly increased compared with healthy people of comparable age $[15,16]$. Methylglyoxal and 3-deoxyglucosone modified DNA were found in sera of breast cancer patients and various AGE modified proteins occurred in their tumor tissues [17]. The levels of AGEs are increased in the saliva of myeloma patients with bone lesions [18]. Histone proteins are particularly susceptible to glycation because of their long half-lives and the nucleophilic tails of their molecules 
that undergo extensive regulatory modifications. Intense histone glycation has been detected in breast tumors [19]. The structure of histone H2A is changed by methylglyoxal and generates highly immunogenic amorphous aggregates with implications in the autoimmune responses associated with cancer [20]. The modification of prohibitin, a tumour suppressor, by glycation results in a loss of its tumor suppressor function with associated complications in HER2/ neu negative invasive breast ductal carcinoma [21].

In vitro and in vivo studies have demonstrated that AGE treatment promotes cancer cell growth, migration and invasion [22-24]. Fluorescent AGEs were found to be increased by $58.63 \%$ in animal models of lung cancer compared with the control group. A RAGE neutralizing antibody significantly inhibits lung metastasis in an established mouse model [25]. Thus, a link between AGEs and lung cancer pathogenesis was established. Also, AGE treatment of estrogen receptor positive (ER+) breast cancer cells altered ER phosphorylation and promoted resistance to tamoxifen therapy [4].

Advanced glycation end products exert adverse effects at the cellular and molecular levels by directly interacting with macromolecules. These include changing existing protein structures, protein misfolding, altering enzyme or receptor functionality and activity, and inducing mutations for example single strand breaks, and unwinding of DNA. However, the binding of an AGE to the receptor for advanced glycation end products (RAGE) activates a multitude of signalling cascades, which leads multiple pathological effects $[2,13]$.

In addition to increased levels of AGEs, overexpression of RAGE has been demonstrated in various types of cancer [26-31]. As a member of the immunoglobulin superfamily of cell surface molecules, RAGE mediates a variety of cellular responses. A significant association between RAGE expression and tumor size, depth of stromal or lymphovascular invasion, metastasis, and the clinical stage of cancers has been observed. For example, RAGE was progressively upregulated from cervicitis to cervical intraepithelial neoplasia and cancer [26]. In ovarian cancer tissue, RAGE gene was overexpressed compared to values in adjacent noncancerous tissue [27]. Expression of RAGE is significantly higher in prostate cancer lesions compared with prostatitis $(\mathrm{p}<0.01)$ and benign prostatic hyperplasia $(p<0.0001)$ [28]. Similarly, the level of RAGE was higher in clear cell renal cell carcinoma tissues than in adjacent normal tissues [29]. The RAGE is a critical promoter for the transition of premalignant epithelial precursors to invasive pancreatic cancer and is overexpressed in human pancreatic tumors but not in adjacent normal ducts [30,31].

Interaction between AGE-RAGE triggers the activation of several molecular signaling pathways, which contributes to tumor development, migration and metastasis. The interaction of AGERAGE activates NADPH oxidase, leading to increased intracellular oxidative stress. The increase in reactive oxygen species (ROS) activates NF- $\kappa \mathrm{B}[32,33]$. Activation of NF- $\kappa \mathrm{B}$ increases cytokine, such as IL- 6 and TNF- $\alpha$, secretion, followed by lymphoid and myeloid immune cells recruitment into the tumor microenvironment leading to an inflammatory response [34]. Chronic inflammation and increased oxidative stress are two of the main hallmarks of cancer [35]. AGE-mediated inflammatory responses and oxidative stress may lead to cancer onset and/or its progression. A study of pancreatic cancer cells demonstrated that CML treatment

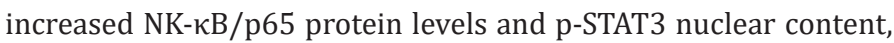
which induced the transcriptional activity of the STAT3 target genes, NFATC1 and PIM1 [24]. Previous studies by us and other researchers have shown that AGEs regulate cancer cell migration via extracellular signal regulated kinase (ERK) phosphorylation [22,36,37]. Methylglyoxal triggers metastasis of breast cancer cells through activation of the MEK/ERK/SMAD1 pathway [38]. Glucose-derived AGEs enhance human gastric cancer metastasis through the RAGE/ERK/Sp1/MMP2 cascade [16]. In oral cancer, AGEs increase ERK phosphorylation leading to Nrf-2 inhibition and Bcl-xl upregulation. This subsequently suppresses p53 and Bax expression and increases cancer cell survival [39].

The pathological implications of RAGE gene polymorphisms in cancer have been reported [40]. The SNP rs1800625 in RAGE gene was significantly associated with gastric cancer risk and tumor clinical stage [41]. This SNP was also associated with late-stage and large-size oral tumors [42]. Cervical cancer patients with genotypes TA/AA in RAGE rs1800624 tend to have moderate-to-poor cell differentiation and pelvic lymph node metastasis compared to those with genotype TT [43].

The adverse effects of AGEs, RAGE and their links to cancer means strategies to prevent or reduce AGEs accumulation could provide health benefits. Dietary-AGE restriction has been shown to reduce circulating AGE levels in patients with chronic kidney disease, metabolic syndrome, and diabetes [44]. The 'Mediterranean diet', which is rich in antioxidants (e.g. polyphenols and $\alpha$-tocopherol), reduces serum AGEs in elderly adults [45]. Dietary intervention and physical activity have also been shown to be viable options to reduce the levels of AGE in the circulation of ER+ breast cancer survivors [4]. Therefore, the application of dietary restriction and raising dietary and lifestyle awareness may be useful in AGE reduction and cancer prevention.

Cross-link breakers of AGE, such as alagebrium chloride (ALT711), and AGE adsorbents (AST-120) reduce AGEs accumulation and block AGE-induced intracellular ROS synthesis in vivo $[46,47,48]$. Soluble RAGE (sRAGE), a naturally occurring antagonist of RAGE, can prevent the adverse effects of RAGE-signaling [49]. An inverse association was found between higher serum concentrations of sRAGE and reduced incident of pancreatic cancer in postmenopausal women [50]. Thus, AGE cross-link breakers and sRAGE have potential clinical applications as a cancer protective and therapeutic reagent. 


\section{Conclusion}

Studies to date have shown that AGEs and RAGE are clearly implicated in the pathogenesis of cancer. AGE accumulation in the body increase the risk of cancer initiation and their progression by modifying the genome, functional proteins and activating aberrant AGE-RAGE cell signaling. However, further investigations are necessary to realize their clinical potential in cancer diagnosis by screening of tissue or plasma/sera AGEs, tissue RAGE, circulating sRAGE, and RAGE gene polymorphisms. The development of novel strategies for cancer prevention and treatment by inhibiting AGEs formation or targeting AGEs-RAGE signalling also require more studies.

\section{Conflict of Interest}

The authors declare about no conflict of interest.

\section{References}

1. Henning C, Glomb MA (2016) Pathways of the Maillard reaction under physiological conditions. Glycoconj J 33(4): 499-512.

2. Fournet M, Bonté F, Desmoulière A (2018) Glycation Damage: A Possible Hub for Major Pathophysiological Disorders and Aging. Aging Dis 9(5): 880-900.

3. Scheijen JLJM, Clevers E, Engelen L, Dagnelie PC, Brouns F, et al. (2016) Analysis of advanced glycation endproducts in selected food items by ultra-performance liquid chromatography tandem mass spectrometry: Presentation of a dietary AGE database. Food Chem 190: 1145-1150.

4. Walter KR, Ford ME, Gregoski MJ, Kramer RM, Knight KD, et al. (2019) Advanced glycation end products are elevated in estrogen receptor-positive breast cancer patients, alter response to therapy, and can be targeted by lifestyle intervention. Breast Cancer Res Treat 173(3): 559-571.

5. Singh VP, Bali A, Singh N, Jaggi AS (2014) Advanced glycation end products and diabetic complications. Korean J Physiol Pharmacol 18(1): 1-14.

6. Nowotny K, Jung T, Höhn A, Weber D, Grune T (2015) Advanced glycation end products and oxidative stress in type 2 diabetes mellitus. Biomolecules 5(1): 194-222.

7. Jujić A, Östling G, Persson M, Engström G, Nilsson PM, et al. (2019) Skin autofluorescence as a measure of advanced glycation end product levels is associated with carotid atherosclerotic plaque burden in an elderly population. Diab Vasc Dis Res 16(5): 466-473.

8. Turner DP (2017) The Role of Advanced Glycation End-Products in Cancer Disparity. Adv Cancer Res 133: 1-22.

9. Bellier J, Nokin MJ, Lardé E, Karoyan P, Peulen O, et al. (2019) Methylglyoxal, a potent inducer of AGEs, connects between diabetes and cancer Diabetes Res Clin Pract 148: 200-211.

10. Giri B, Dey S, Das T, Sarkar M, Banerjee J, (2018) Chronic hyperglycemia mediated physiological alteration and metabolic distortion leads to organ dysfunction, infection, cancer progression and other pathophysiological consequences: An update on glucose toxicity. Biomed Pharmacother 107: 306-328.

11. Palanissami G, Paul SFD (2018) RAGE and Its Ligands: Molecular Interplay Between Glycation, Inflammation, and Hallmarks of Cancer-a Review. Horm Cancer 9(5): 295-325.

12. Van Heijst JW, Niessen HW, Hoekman K, Schalkwijk CG (2005) Advanced glycation end products in human cancer tissues: detection of Nepsilon-(carboxymethyl)lysine and argpyrimidine. Ann N Y Acad Sci 1043: 725-733.

13. Schröter D, Höhn A (2018) Role of Advanced Glycation End Products in Carcinogenesis and their Therapeutic Implications. Curr Pharm Des 24(44): 5245-5251.
14. Sakellariou S, Fragkou P, Levidou G, Gargalionis AN, Piperi C, et al. (2016) Clinical significance of AGE-RAGE axis in colorectal cancer: associations with glyoxalase-I, adiponectin receptor expression and prognosis. BMC Cancer 16:174.

15. Kuniyasu H, Oue N, Wakikawa A, Shigeishi H, Matsutani N, et al. (2002) Expression of receptors for advanced glycation end-products (RAGE) is closely associated with the invasive and metastatic activity of gastric cancer. J Pathol 196(2): 163-170.

16. Deng R, Mo F, Chang B, Zhang Q, Ran H, et al. (2017) Glucose-derived AGEs enhance human gastric cancer metastasis through RAGE/ERK/ Sp1/MMP2 cascade. Oncotarget 8(61): 104216-104226.

17. Synold T, Xi B, Wuenschell GE, Tamae D, Figarola JL, et al. (2008) Advanced glycation end products of DNA: quantification of N2-(1-Carboxyethyl)-2'-deoxyguanosine in biological samples by liquid chromatography electrospray ionization tandem mass spectrometry. Chem Res Toxicol 21(11): 2148-2155.

18. Katz J, Moreb J, Baitinger C, Singer C, Caudle RM (2017) Advanced glycation endproducts (AGEs) in saliva of patients with multiple myeloma - a pilot study. Leuk Lymphoma 58(12): 2934-2938.

19. Zheng Q Omans ND, Leicher R, Osunsade A, Agustinus AS, et al. (2019) Reversible histone glycation is associated with disease-related changes in chromatin architecture. Nat Commun 10(1): 1289.

20. Mir AR, Moinuddin, Habib S, Khan F, Alam K, Ali A (2016) Structural changes in histone $\mathrm{H} 2 \mathrm{~A}$ by methylglyoxal generate highly immunogenic amorphous aggregates with implications in auto-immune response in cancer. Glycobiology 26(2): 129-1241.

21. Korwar AM, Bhonsle HS, Chougale AD, Kote SS, Gawai KR, et al. (2012) Analysis of AGE modified proteins and RAGE expression in HER2/neu negative invasive ductal carcinoma. Biochem Biophys Res Commun 419(3): 490-494.

22. Sharaf H, Matou-Nasri S, Wang Q, Rabhan Z, Al-Eidi H, et al. (2015) Advanced glycation endproducts increase proliferation, migration and invasion of the breast cancer cell line MDA-MB-231. Biochim Biophys Acta 1852(3):429-441

23. Rodriguez-Teja M, Gronau JH, Breit C, Zhang YZ, Minamidate A, et al. (2015) AGE-modified basement membrane cooperates with Endo180 to promote epithelial cell invasiveness and decrease prostate cancer survival. J Pathol 235(4): 581-592.

24. Menini S, Iacobini C, de Latouliere L, Manni I, Ionta V, et al. (2018) The advanced glycation end-product $\mathrm{N} \epsilon$-carboxymethyllysine promotes progression of pancreatic cancer: implications for diabetes-associated risk and its prevention. J Pathol 245(2): 197-208.

25. Khan H, Khan MS, Ahmad S (2018) The in vivo and in vitro approaches for establishing a link between advanced glycation end products and lung cancer. J Cell Biochem 119(11): 9099-9109.

26. Zhu X, Jin L, Zou S, Shen Q, Jiang W, et al. (2013) Immunohistochemical expression of RAGE and its ligand (S100A9) in cervical lesions. Cell Biochem Biophys 66(3): 843-850.

27. Rahimi F, Karimi J, Goodarzi MT, Saidijam M, Khodadadi I, et al. (2017) Overexpression of receptor for advanced glycation end products (RAGE) in ovarian cancer. Cancer Biomark 18(1): 61-68.

28. Aboushousha T, Lashen R, Abdelnaser K, Helal N, Moussa M, et al. (2019) Comparative Expression of RAGE and SOX2 in Benign and Malignant Prostatic Lesions. Asian Pac J Cancer Prev 20(2): 615-620.

29. Guo Y, Zhang HC, Xue S, Zheng JH (2019) Receptors for advanced glycation end products is associated with autophagy in the clear cell renal cell carcinoma. J Cancer Res Ther 15(2): 317-323.

30. Kang R, Loux T, Tang D, Schapiro NE, Vernon P, et al. (2012) The expression of the receptor for advanced glycation endproducts (RAGE) is permissive for early pancreatic neoplasia. Proc Natl Acad Sci U S A 109(18): 7031-7036.

31. Kang R, Hou W, Zhang Q, Chen R, Lee YJ, et al. (2014) RAGE is essential 
for oncogenic KRAS-mediated hypoxic signaling in pancreatic cancer Cell Death Dis 5: e1480.

32. Lin L, Park S, Lakatta EG (2009) RAGE signaling in inflammation and arterial aging. Front Biosci (Landmark Ed) 14:1403-1413.

33. Xie J, Méndez JD, Méndez-Valenzuela V, Aguilar-Hernández MM (2013) Cellular signalling of the receptor for advanced glycation end products (RAGE). Cell Signal 25(11): 2185-2197.

34. Qu X, Tang Y, Hua S (2018) Immunological Approaches Towards Cancer and Inflammation: A Cross Talk. Front Immunol 9: 563.

35. Hanahan D, Weinberg RA (2011) Hallmarks of cancer: the next generation. Cell 144(5): 646-674.

36. Matou-Nasri S, Sharaf H, Wang Q Almobadel N, Rabhan Z, et al. (2017) Biological impact of advanced glycation endproducts on estrogen receptor-positive MCF-7 breast cancer cells. Biochim Biophys Acta Mol Basis Dis 1863(11): 2808-2820.

37. Ko SY, Ko HA, Shieh TM, Chang WC, Chen HI, et al. (2014) Cell migration is regulated by AGE-RAGE interaction in human oral cancer cells in vitro. PLoS One 9(10): e110542.

38. Nokin MJ, Bellier J, Durieux F, Peulen O, Rademaker G, et al. (2019) Methylglyoxal, a glycolysis metabolite, triggers metastasis through MEK/ ERK/SMAD1 pathway activation in breast cancer. Breast Cancer Res 21(1):11

39. Ko SY, Ko HA, Shieh TM, Chi TC, Chen HI, et al. (2017) Advanced glycation end products influence oral cancer cell survival via Bcl-xl and Nrf-2 regulation in vitro. Oncol Lett 13(5): 3328-3334.

40. Serveaux-Dancer M, Jabaudon M, Creveaux I, Belville C, Blondonnet R, et al. (2019) Pathological Implications of Receptor for Advanced Glycation End-Product (AGER) Gene Polymorphism. Dis Markers 2019: 2067353.

41. Hu D, Liu Q Lin X, Zhang H, Lin J, et al. (2019) Association of RAGE gene four single nucleotide polymorphisms with the risk, invasion, metastasis and overall survival of gastric cancer in Chinese. J Cancer 10(2): 504509.
42. Su S, Chien M, Lin C, Chen M, Yang S (2015) RAGE gene polymorphism and environmental factor in the risk of oral cancer. J Dent Res 94(3): 403-411.

43. Lee CY, Ng SC, Hsiao YH, Yang SF, Hsu CF, et al. (2018) Impact of the Receptor for Advanced Glycation End Products Genetic Polymorphisms on the Progression in Uterine Cervical Cancer. J Cancer 9(21): 3886-3893.

44. Vlassara H, Cai W, Tripp E, Pyzik R, Yee K, et al. (2016) Oral AGE restriction ameliorates insulin resistance in obese individuals with the metabolic syndrome: a randomised controlled trial. Diabetologia 59(10): 2181-2192.

45. Lopez-Moreno J, Quintana-Navarro GM, Delgado-Lista J, Garcia-Rios A Delgado-Casado N, et al. (2016) Mediterranean Diet Reduces Serum Advanced Glycation End Products and Increases Antioxidant Defenses in Elderly Adults: A Randomized Controlled Trial. J Am Geriatr Soc 64(4): 901-904.

46. Ueda S, Yamagishi S, Takeuchi M, Kohno K, Shibata R, et al. (2006) Oral adsorbent AST-120 decreases serum levels of AGEs in patients with chronic renal failure. Mol Med 12(7-8): 180-184.

47. Kranstuber AL, Del Rio C, Biesiadecki BJ, Hamlin RL, Ottobre J, et al. (2012) Advanced glycation end product cross-link breaker attenuates diabetes-induced cardiac dysfunction by improving sarcoplasmic reticulum calcium handling. Front Physiol 3: 292.

48. Yamagishi S. (2012) Potential clinical utility of advanced glycation end product cross-link breakers in age- and diabetes-associated disorders. Rejuvenation Res 15(6): 564-572.

49. Ahmad S, Khan H, Siddiqui Z, Khan MY, Rehman S, et al. (2018) AGEs, RAGEs and s-RAGE; friend or foe for cancer. Semin Cancer Biol 49: 44-55.

50. White DL, Hoogeveen RC, Chen L, Richardson P, Ravishankar M, et al. (2018) A prospective study of soluble receptor for advanced glycation end products and adipokines in association with pancreatic cancer in postmenopausal women. Cancer Med 7(5): 2180-2191. 